\title{
PAPERS
}

\section{Depression after stroke: a hospital treatment survey}

\author{
M. L. LIM* \\ B.Med.Sci., B.M., B.S. \\ S. B. J. EBRAHIM $\dagger$ \\ M.Sc., M.R.C.P., M.R.C.G.P.
}

University of Nottingham Medical School, Queens Medical Centre, Nottingham NG7 2UH and Department of
Health Care of the Elderly, Sherwood Hospital, Nottingham NG5 IPD

\section{Summary}

Treatment with anti-depressant drugs of 61 inpatients admitted on account of stroke was studied. Eighteen patients (30\%) were being so treated. Only 5 patients $(17 \%)$ with dysphasia were being treated with anti-depressant drugs compared with 13 patients (41\%) without dysphasia $(P<0.05)$. Dosage levels used were generally low and only one patient had been referred for a psychiatric opinion. We suggest that the difference in anti-depressant usage is because dysphasic patients are more difficult to assess and therefore less likely to have depressive symptoms recognized and treatment given. We also think that psychiatric referral should be used more often for assessment of stroke patients and for advice about treatment.

KEY WORDS: stroke, depression, anti-depressant drugs.

\section{Introduction}

Depression following stroke is common (Licht, 1975; Slater and Roth, 1969) and may be a cause of failure of rehabilitation (Adams and Hurwitz, 1963; Hook and Espmark, 1973; Brocklehurst et al., 1978). The recognition of depression in a patient who has experienced a stroke may be difficult but has to be based on knowledge of predisposing factors (such as a past history of depressive illness or lack of support from relatives), the manifestations of depression (sleep disturbance, diurnal mood variation, anorexia, psychomotor retardation, hypochondriacal concern over minor handicaps, self-blame, tearfulness) and the time relationship with the stroke itself.

Recognition of this serious complication is important because it is potentially reversible. We have

\footnotetext{
*Present address: Louth County Hospital, Lincolnshire.

†Present address: University of Nottingham Medical School, Queens Medical Centre, Nottingham NG7 2UH.
}

examined the extent to which depression is recognized amongst hospitalized stroke patients using treatment with anti-depressant drugs as an index of recognition. We have also looked for relationships between recognition of depression and the presence of dysphasia, the side of the cerebral lesion, the time since the stroke, age and sex of the patient and whether the patient is on a geriatric or acute medical ward.

\section{Materials and methods}

All patients currently on the acute medical wards of City Hospital and the assessment and rehabilitation wards of Sherwood Hospital, Nottingham were identified from a register of stroke patients kept for research purposes. The medical records and treatment cards were examined and details of age, sex, date of stroke, side of stroke, presence or absence of dysphasia, psychiatric referral and drug treatment were recorded. Cross tabulations were made and chisquare tests of significance applied.

\section{Results}

Sixty-one patients were studied, of whom 9 had had a previous ipsilateral stroke (6 patients with bilateral strokes were not included). There were 25 $(41 \%)$ males and $36(59 \%)$ females with an age range of 55-93 years (median 75 years). Thirty-three (54\%) had suffered a right-sided hemiplegia and $28(46 \%)$ a left-sided hemiplegia. Twenty-nine (48\%) had dysphasia as judged by the admitting house officer. Eighteen (30\%) were receiving anti-depressant drugs and one other patient was receiving imipramine for urinary incontinence.

No patient had been treated with electro-convulsive therapy and only one patient had been seen by a psychiatrist. Eight patients were being treated with mianserin, 5 with amitriptyline, 3 with imipramine, 
one with nomifensine and one with dothiepin. The highest daily dose of mianserin prescribed was $30 \mathrm{mg}$, but $10-20 \mathrm{mg}$ was more commonly administered. For amitriptyline and imipramine, the usual dose prescribed was $25 \mathrm{mg}$ daily. No patient with a contraindication to treatment such as recent myocardial infarction, heart block or mania was prescribed antidepressants and none was taking drugs known to interact with anti-depressants. Treatment with antidepressants was started from 2 to 20 weeks after onset of stroke (mean 10 weeks).

Time since stroke, age and sex of patient did not affect the likelihood of anti-depressant drugs being used. Twenty-eight $(46 \%)$ patients were on acute medical wards and $33(54 \%)$ on geriatric wards and there was no difference in the proportion of patients being treated for depression. Five (17\%) of 32 patients with dysphasia were being treated with antidepressants compared with $13(41 \%)$ of 29 patients without dysphasia $(P<0.05)$. Significantly $(P<0.01)$ more patients with left hemiplegia were receiving anti-depressants, 13 of 28 compared with 5 of 33 with right hemiplegia. The duration of time since admission to survey was similar for patients with right and left hemiplegia.

\section{Discussion}

Previous studies, based on psychiatric interviews and validated questionnaires, suggest that the prevalence of depression in stroke patients is from 30\% amongst a group of patients referred to a stroke clinic (Robinson and Price, 1982) to 45\% amongst a hospitalized group of patients (Folstein, Maiberger and McHugh, 1977). Thirty percent (95\% confidence interval $19-42 \%$ ) of our patients were receiving antidepressants, but significantly more patients without dysphasia and with left hemiplegia were being treated. Patients with left hemiplegia are more likely to suffer from irritability, loss of interest and difficulty concentrating than those with right hemiplegia, although depression scores in the 2 groups have been reported as similar by Folstein et al. (1977). However, Robinson and Price (1982) found that right hemiplegic patients were significantly more depressed than left hemiplegic or brainstem stroke patients. This evidence is supported by the findings of Lishman (1978) who reported that left cerebral hemisphere lesions produced by head injury were more closely associated with psychiatric disability.

Speech impairment and right hemiplegia are closely related clinical findings and consequently their relationship with anti-depressant use in our study is similar. On balance, it seems possible that dysphasic and right hemiplegic patients are as likely (or even more likely) to become depressed as left hemiplegic patients. It seems probable that dysphasic patients are less likely to have their depression recognized and receive treatment. They are often n able to clearly state their symptoms and are therefore more difficult to assess.

Relationships between depression and severity $\overrightarrow{\mathrm{H}}$ stroke and impaired intellectual function are difficuift to determine. We found no association betweẹ length of stay in hospital (a possible indicator 9 f stroke severity) and use of anti-depressants. Intellee tual function is difficult to measure in dysphasie patients and therefore no comparison of anti-depressant use could be made. However, emotional labilits was often recorded as the reason for starting antidepressant treatment.

Mental barriers to recovery from stroke have beeg defined (Adams and Hurwitz, 1963) and inclume behavioural abnormalities due to organic bratm damage in both right or left cerebral hemisphere Behaviour in dysphasic patients may vary depending on the type of dysphasia. Those with primary motot dysphasia (Broca's dysphasia) characteristically ree spond in a way that appears appropriate and age often depressed, tearful and distressed by their errors when tested. In contrast, patients with primary sensory dysphasia (Wernicke's dysphasia) can pre sent with dramatic psychiatric syndromes. They age usually unaware of their speech difficulties and may be euphoric. They may also feel that their speegh normal but that of others is abnormal which inasy lead to agitation and paranoid reactions (Geschworis, 1970). Attention has also been drawn to the associo tion between angry reactions such as cursing, biting, scratching and throwing objects which may occur patients with primary sensory dysphasia (Fishe 1970). There is, however, no evidence that stroke patients with dysphasia are less likely to be depressed than others.

Depression is not the only 'psychiatric' proble that may occur following a stroke. Problems of personality change, acute confusional state, percep tual difficulties, memory impairment, emotion lability and denial may all occur and hinder rehabi tation (Lishman, 1978; Licht, 1975; Adams and Hurwitz, 1963). Unfortunately, many of these pro lems are not directly treatable but recognition may help the patient and particularly the family. Disru tion of household and leisure activities occurs in over a third of main carers of stroke patients in the firsi month falling to 6-10\% by the end of the first yeæ (Brocklehurst et al., 1978). This may manifest itself if a raised incidence of minor psychiatric problems in spouses of stroke patients.

Dosage levels of anti-depressants used in oư survey were generally low and it is possible thg patients might benefit from larger doses. Psychiatree opinions should probably be sought more often particularly with regard to assessment of patien 
with dysphasia and for advice about drugs and dosage and type of treatment. There is also need for an appraisal of the effectiveness of anti-depressants in depression following stroke, both in improving mood and functional recovery.

\section{Acknowledgments}

We thank Dr G. P. Mulley for useful criticism of the manuscript.

\section{References}

ADAMS, G.F. \& HURWITZ, L.J. (1963) Mental barriers to recovery from strokes. Lancet, ii, 533 .

BRoCKlehURST, J.C., ANDREWS, K., MoRRIS, P.E., RichardS, B. \& LAYCOCK, P.T. (1978) Medical, social and psychiatric aspects of stroke. Final report, Department of Geriatrics, University of Manchester.

FISHER, C.M. (1970) Anger associated with dysphasia. Transactions of the American Neurological Association, 95, 240.
Folstein, M.F., Maiberger, R. \& MCHugh, P.R. (1977) Mood disorder as a specific complication of stroke. Journal of Neurology, Neurosurgery and Psychiatry, 40, 1018.

GESCHWIND, N. (1970) In: Behavioural change in cerebro-vascular disease (Ed. A.L. Benton), 1st edn., p. 34. Harper and Row, New York.

HooK, O., EsPMARK, S. (1973) Stroke before 50. A follow-up study of vocational and psychological adjustment. Scandinavian Journal of Rehabilitation Medicine (Supplement), 2, 80.

LICHT, S. (1975) Stroke and its rehabilitation, Ist edn., p. 409. Waverly Press, Baltimore.

Lishman, W.A. (1978) Organic Psychiatry. The Psychological Consequence of Cerebral Disorder, 1st edn., p. 460. Blackwell Scientific Publications, Oxford.

Robinson, R.G. \& PRICE, T.R. (1982) Post stroke depressive disorders: a follow up study of 103 patients. Stroke, 13, 635 .

Slater, E. \& RoTH, M. (1969) Clinical Psychiatry, 3rd edn., p. 593. Balliere, Tindall and Cassell, London.

(Accepted 15 February 1983) 